\title{
Encontros narrativos: mulheres pesquisadoras em meio à pandemia
}

\author{
Narrative encounters: women researchers amidst the pandemic
}

\author{
Ana Paula Dellbrügger' ${ }^{\mathbf{1}}$, Mariel Corrêa de Oliveira', Camilla Rodrigues Guerra', Claudia Schramm \\ Scaramussa', Joice Guerra Zorzi ${ }^{2}$, Éllen Cristina Ricci ${ }^{\mathbf{3}}$, Tatiana Dimov ${ }^{\mathbf{1}}$
}

DOI: 10.1590/0103-11042021E114

RESUMO A pandemia de Covid-19 gerou uma grave ruptura do cotidiano, submetendo as pessoas ao distanciamento e ao isolamento social e exigindo o desempenho de diversos papéis ocupacionais em um só ambiente. Diante disso, 11 mulheres de 2 universidades federais se uniram para fazer ciência e produzir grupos de ajuda e suporte mútuo virtuais para a população de 6 públicos-alvo diferentes. Neste artigo, apresenta-se uma reflexão sobre os caminhos percorridos pelas autoras a partir de aspectos semelhantes e singulares, dificuldades e privilégios identificados que perpassam suas vidas. Recorreu-se à cartografia para desenvolver este texto pela possibilidade de romper a lógica positivista acadêmica e expressar sentimentos e subjetividades. Entendendo tal experiência como irreprodutível pela técnica, construíram-se narrativas a partir da pergunta: "Como a minha história, constituindo-se mulher, afeta a minha participação nesta atividade de pesquisa?". Depois das leituras, elencaram-se oito categorias de análise e inferiu-se que gênero, raça/etnia e classe podem ser privilégios ou obstáculos a depender da sua expressão: masculino/ feminino, branco/negro, alta/baixa. Para as mulheres, a divisão sexual e a dupla jornada de trabalho, assim como a maternidade, ampliam a desvantagem causada pelo gênero.

PALAVRAS-CHAVE Saúde mental. Gênero. Pandemia. Mulher. Narrativa.

\begin{abstract}
The Covid-19 pandemic caused a serious rupture in everyday life, subjecting people to social distancing and isolation, demanding performances of several occupational roles in the same environment. Thus, eleven women from two federal universities came together to do science and produce mutual virtual support groups for the population for six different target-groups. In this article, we present a reflection on the authors'stories from similar and singular aspects, difficulties and privileges identified that permeate our lives. We used cartography to develop this article due to the possibility of breaking the academic positivist logic and expressing feelings and subjectivities. Understanding this experience as irreproducible by its technique, narratives were built from the question: "How does my history as a woman affect my participation in this research activity?". After the readings, eight categories of analysis were listed and it was inferred that gender, race/ethnicity, and class may be privileges or obstacles depending on their expression: male/female, white/ black, high/low. For women, the sexual division of labor, double working hours, and motherhood amplify

the disadvantage caused by gender.
\end{abstract}

1 Universidade Federal de Santa Maria (UFSM) Santa Maria (RS), Brasil. tatiana.dimov@ufsm.br

2 Universidade Federal do Rio Grande do Sul (UFRGS)

- Porto Alegre (RS), Brasil.

3 Universidade Federal de Pelotas (UFPel) - Pelotas (RS), Brasil.
KEYWORDS Mental health. Gender. Pandemics. Women. Narration. 


\section{Introdução e justificativa}

A atual pandemia, que se instalou em praticamente todos os países, tem gerado uma grave ruptura do cotidiano, submetendo as pessoas ao distanciamento e ao isolamento social e exigindo que desempenhem diversos papéis em um mesmo ambiente, muitas vezes limitado. Tudo isso, aliado ao medo e à preocupação constante de contaminação, fez - e continua fazendo - com que a saúde mental de muitos seja diretamente afetada.

Diante disso, uma estudante de graduação de uma universidade pública federal, jovem mulher/filha/irmã de 24 anos, assim que suas aulas foram suspensas por causa da pandemia, lançou uma enquete na sua rede social perguntando: "Como vocês estão se sentindo com a quarentena declarada no Brasil?”. A partir disso, identificou o desconforto emocional de diversos alunos após a suspensão das aulas. A discente, então, pela proximidade com outra mulher/amiga/casada/sem filhos/irmã e professora da área de saúde mental, entrou em contato com esta, enviando algumas imagens das respostas, e ambas se sensibilizaram em acolher todas e todos que estavam vivendo agudamente os desconfortos emocionais diante de uma emergência sanitária magnitude.

Inicialmente, analisaram materiais sobre Telemonitoramento ${ }^{1}$ e Grupos de Ajuda e Suporte Mútuos ${ }^{2}$ para criar um método de cuidado por meio de ferramentas virtuais. Assim, surgiu um Grupo de Escuta on-line com convite aberto a qualquer pessoa, em que os participantes conversam sobre assuntos diversos do cotidiano. Os grupos ocorrem desde o final de março/2020, duas vezes por semana, com duração de aproximadamente uma hora e meia e mediação das idealizadoras do projeto. Os participantes relatam seus dias em quarentena, compartilham experiências diárias e conversam sobre assuntos de interesse mútuo. Além disso, criou-se um grupo no WhatsApp para que os participantes possam manter o contato diário e trocar experiências e dicas para enfrentar o período de isolamento social.
Uma amiga dessa professora, também professora universitária, mãe/esposa/filha/irmã, soube do projeto de extensão Grupo de Escuta e propôs ampliar o trabalho, desenvolvendo uma pesquisa e buscando financiamento. $\mathrm{O}$ tempo era curto, e essas mulheres escreveram, em menos de 15 dias, um projeto de pesquisa robusto, com várias camadas de análises e 6 perfis populacionais diferentes.

O financiamento não saiu, mas essas três mulheres decidiram continuar mesmo assim. Continuar como? Quem vai aceitar entrar voluntariamente em uma pesquisa? Como cuidar e construir um espaço colaborativo? A partir das suas redes de afetos, foram encontrando mais mulheres, estudantes, profissionais da saúde/irmãs/ filhas/namoradas e, também, um homem estudante/pai/filho/namorado. De certa forma, pode-se dizer que o próprio grupo de pesquisa tem se tornado um grupo de apoio informal, pois, ao mesmo tempo que se faz o trabalho técnico, tecem-se relações de afeto, apoio e acolhimento e trocam-se desabafos e estratégias de autocuidado. Assim, frisa-se que a participação das autoras em grupos de apoio e grupos focais não compõe a metodologia deste artigo.

\section{Objetivo}

O presente artigo busca refletir sobre os caminhos percorridos das autoras até o momento da realização da pesquisa, identificando aspectos semelhantes e singularidades que atravessam a vida de todas as mulheres desse grupo.

\section{Material e métodos}

Recorremos à cartografia para a construção deste artigo, pois tal abordagem teórica permite romper com a lógica positivista acadêmica e expressar sentimentos, afetos e subjetividades por meio da escrita. Richter e Oliveira $^{3(29)}$ declaram que 
Em cartografia, o que interessa é o que se passa entre, o que extrapola fronteiras, o que transborda as bordas, as delimitações. Busca-se pensar e sentir o processo, sendo o pesquisador o agente que se coloca como pesquisa juntamente com seu objeto.

Este artigo não procura um resultado ou uma conclusão de fatos, mas, sim, narrar e discutir o processo de produção de ciência de um grupo de mulheres a partir do seu cotidiano singular em meio à pandemia de Covid-19.

Na fase inicial deste trabalho, refletimos sobre como é a participação de mulheres na construção de conhecimento e os impactos dessa atividade neste momento de pandemia. O cenário do estudo foram narrativas do cotidiano das autoras deste artigo com trajetórias que expressam seus modos de ser e de viver. Tais narrativas encontram e marcam o desafio de nascer mulher e produzir ciência nesta sociedade contemporânea, refletindo sobre os lugares que ocupamos no mundo, os papéis ocupacionais que desempenhamos e reconhecendo nossas diferenças e semelhanças.

Partindo do entendimento de que a experiência é irreprodutível pela técnica, optamos pela construção de narrativas que se inspiram, em sua sistematização, na proposta de Walter Benjamin 4 . Tal autor coloca que "o narrador retira da experiência o que ele conta: sua própria experiência ou a relatada pelos outros"4(201), de modo a incorporar as coisas narradas à experiência de quem o ouve. Narrar assemelha-se ao trabalho do artesão que molda o barro, sendo uma forma "artesanal"4(205) de comunicação, sendo importante fazer a distinção entre narrativa e informação, pois a informação é valorada no momento em que é nova e "só vive nesse momento, precisa entregar-se inteiramente a ele e sem perda de tempo tem que se explicar nele"4(204), enquanto a narrativa desenvolve-se temporalmente, conservando sua força ao longo desse período 4 .

A narrativa seria composta por várias experiências que se superpõem e formam finas camadas em uma composição simultaneamente única e múltiplas ${ }^{4}$. A junção das múltiplas experiências forma uma 'experiência coletiva', que pode ser comparada a uma escada na qual o narrador move-se de cima a baixo.

Por fim, tem-se o narrador cuja tarefa é trabalhar a matéria-prima da experiência, seja ela individual ou aquela que lhe foi confiada, e transformá-la em um produto único, de modo que quem escuta ou lê tal história possa estar em companhia do narrador e partilhar também da sua experiência ${ }^{4}$.

Para a construção do presente trabalho, sete mulheres/autoras/narradoras integrantes de um grupo de pesquisa composto por 12 pessoas (11 mulheres e 1 homem - sendo que esse não participou da construção deste artigo), construíram narrativas a partir da pergunta: "Como a minha história como mulher afeta a minha participação nesta atividade de pesquisa?". Em seguida, fez-se uma leitura delas, na íntegra, e uma discussão sobre quais seriam as categorias de análise, elencando aspectos comuns e singulares nas diferentes produções, o que resultou nas seguintes categorias que serão apresentadas a seguir: 1) A pele branca como marca; 2) Privilégios e participação em pesquisa: desafios de ser mulher na academia com e sem outros marcadores sociais da diferença; 3) Apoio e cuidado mútuo entre elas; 4) Cuidadora: papel da mulher; 5) Profissão de cuidado como escolha?; 6) Diploma como estratégia de libertação; 7) Preconceito e Medo; 8) Ser mulher na linha de frente em um país extremamente desigual. As narrativas serão apresentadas ao longo do texto em itálico e entre aspas, e as narradoras serão identificadas por nomes fictícios de mulheres que admiram

\section{Resultado e análise dos dados}

$$
\begin{array}{r}
\text { Se és uma mulher forte } \\
\text { se proteja com palavras e árvores } \\
\text { e invoca a memória de mulheres antigas. } \\
\text { Gioconda Belli } 5
\end{array}
$$

Não é possível pensar e entender o presente sem considerar toda a história que nos 
traz até aqui. Nesse sentido, a história das mulheres foi e continua sendo invisibilizada, desacreditada e/ou desvalorizada. Tal fato pode ser constatado na falta de referências femininas durante a formação acadêmica e na associação da história do homem como sinônimo de história da humanidade. As causas para isso são inúmeras, mas partem de bases comuns pertencentes a uma sociedade construída com base em marcadores sociais da diferença e pela hierarquização de gênero, raça/etnia e classe, além de valores patriarcais e machistas que desvalorizam todas e todos diferentes do 'padrão ouro' - homem, branco, rico e heterossexual6. Dessa forma, as narrativas das autoras são perpassadas e compreendidas, portanto, por um viés de gênero, classe e raça/etnia.

Os marcadores sociais da diferença dizem respeito à classificação e à diferenciação de certos indivíduos de maneira estigmatizada - sendo os principais gênero, classe social e raça/etnia - e são a base para os diversos estereótipos existentes, ou seja, uma excessiva generalização como verdade universal para toda uma classe de pessoas que possuem características comuns ${ }^{6,7}$. Tais marcadores podem ser compreendidos por três perspectivas: meio de análise, abordagem interseccional e associação de categorias.

Buscamos, em primeiro momento, entender as relações entre gênero, sexualidade, classe, raça/etnia etc., dentro de cada contexto. Em seguida, mobilizamos a noção de marcadores como auxiliar da análise que contribui para compreender a sobreposição de exclusões. Finalmente, fazemos um exercício para encarar as diferenças e as desigualdades em contextos históricos, de modo que a palavra marcador é usada como um substantivo em uma cadeia de significados. Tais perspectivas, quando entrelaçadas, permitem enriquecer as interpretações sobre os modos de diferenciar, nomear, hierarquizar e produzir desigualdades em contextos diversos ${ }^{8}$.

\section{A pele branca como marca}

\author{
Ser branca, indiscutivelmente, facilita com que eu \\ possa fazer pesquisa, quando pensamos sobre a facili- \\ dade de acesso ao (e no) sistema educacional. (Ana). \\ Falo na condição de mulher branca dentro de uma \\ sociedade racista, sexista e capitalista. (Léia).
}

As sete autoras são brancas, e um fator atribuído a tal homogeneidade é a dificuldade que as mulheres negras possuem de ingressar nas universidades devido ao sistema desigual de acesso das populações negras e periféricas à educação ${ }^{9}$. Ao longo dos últimos anos, muitas mulheres negras conseguiram ingressar no ensino superior, mas o número ainda não é significativo, já que elas ainda são minoria no espaço acadêmico. Portanto, não é estranho, no contexto do Rio Grande do Sul, encontrar grupos inteiramente formados por pesquisadoras brancas.

As mulheres negras estão em uma posição incomum nesta sociedade, pois estão na parte inferior da escada do trabalho e possuem condição social geral inferior à de qualquer outro grupo, dado que suportam a opressão machista, classista e, sobretudo, racista - três principais marcadores sociais da diferença ${ }^{10}$. No Brasil, tais mulheres sempre ocuparam a pior posição na hierarquia social, disposta da seguinte forma: homens brancos, mulheres brancas, homens negros/pardos e, então, mulheres negras"1.

Além disso, após a abolição, não houve nenhuma tentativa de reparação histórica e de garantia de direitos. Como consequência, observa-se que a estrutura e a cultura escravocrata permanecem quase inalteradas, pois a maioria das mulheres empregadas domésticas são negras, sendo raras as mulheres negras em cargos de poder ${ }^{12}$, que, mesmo nesse alto status, continuam enfrentando o racismo tanto escancarado quanto sutil da sociedade.

Uma pesquisa realizada em 2018 pelo Instituto de Pesquisa Econômica Aplicada 
(Ipea) mostrou que, dos 6,2 milhões de pessoas que tinham como ocupação o serviço doméstico remunerado, $92 \%$ (5,7 milhões) eram mulheres, das quais cerca de $68,5 \%$ eram negras. Aqui aparecem o marcador classe e a segunda perspectiva de seu entendimento que fala sobre a sobreposição de diferenças e as diversas maneiras de promover a exclusão social. Assim, percebe-se que os marcadores sociais da diferença se interconectam ${ }^{13}$, uma vez que os privilégios ou as desvantagens se acumulam e ainda há muito a percorrer para alcançar uma sociedade igualitária e equalitária.

A convergência destes três marcadores sociais da diferença - gênero feminino, raça/ etnia negra e classe baixa -, combinada com a história escravocrata do Brasil, resulta em um ciclo vicioso em que esse grupo fica preso às oportunidades de trabalhos servis e desvalorizados, de forma que as ancestrais dessas mulheres que foram escravizadas, a avó e a mãe empregada doméstica ou operária e, às vezes, apenas a mulher da geração atual podem trilhar outros rumos e acessar a universidade, embora a grande maioria ainda tenha que continuar o ciclo por falta de oportunidade.

Nesse sentido, tem-se que as vivências de uma mulher branca e de uma mulher negra são completamente diferentes e se diferenciam ainda mais quando se adiciona o fator classe social. No grupo de pesquisa em questão, como já citado, somos todas brancas; e, tendo como base a formação racista do Brasil, tal fato evidencia um privilégio de raça/etnia que se estabelece a partir de nossa branquitude, que nos permite ocupar posições por sermos sistematicamente privilegiadas no que tange ao acesso a recursos materiais e simbólicos desde o colonialismo e o imperialismo ${ }^{\mathbf{1 4}}$.

Nessa perspectiva, Isildinha Nogueira ${ }^{15}$, em sua tese, aponta que a brancura foi sendo construída, histórica e culturalmente, como um ideal a ser seguido. Ideal este que não se finda nas produções individuais, mas organiza a forma como o acesso a uma série de direitos sociais é estruturado. Não é por acaso que o corpo branco é aquele que terá mais condições de ter acesso à moradia digna, oportunidades de emprego, transferência de riqueza herdada entre as gerações e, por fim, acessar e permanecer nos espaços voltados para a educação ${ }^{14,15}$. Aqui, reafirma-se que as sete autoras deste artigo são mulheres brancas e destaca-se a necessidade de, apesar do recorte de gênero, pensar nas limitações da (re)produção da ciência em um país marcadamente racista.

\section{Ser a primeira a ingressar na universidade - Classe, gênero e oportunidade}

Foi, portanto, significado como o sucesso do imigrante nas terras novas quando meus pais, tias e tios puderam acessar o ensino superior e, com isso, galgar um status mais avantajado na classe média. (Rosa).

Neste artigo, o marcador classe é muito significativo, pois embora todas as autoras sejam brancas, seis das sete são as primeiras da família a entrar em uma universidade pública e/ou obter o diploma universitário.

Me formei e comemorei essa grande conquista, a primeira mulher da família a ser graduada. (Maria).

Passei no vestibular depois de alguns anos de terapia que não me custaram um centavo de moeda real, mas muitas transformações, angústias, raivas, desejos, intensas emoções revisitadas!!! Fui a primeira da família a chegar lá! (Cristina).

Observa-se também que alcançar a possibilidade de um diploma aparece não apenas como conquista individual, mas coletiva, considerado como resultado do esforço de toda a família:

No ano de 2017, aos 16 anos, fui aprovada no curso de Psicologia na UFSM, realizando não só um sonho meu, mas também um sonho de meus pais, que por razões econômicas não puderam terminar o ensino médio e ingressar no ensino superior. (Tereza). 
Entendo que ser mulher e pesquisadora no Brasil, quando se nasce na classe trabalhadora, ao mesmo tempo que é um direito, ainda é um privilégio. Não vejo minha trajetória pelas lentes meritocráticas, mas sim pelo reconhecimento de que se eu pude ser a primeira mulher da minha matrilinearidade a ter acesso ao ensino superior, é porque, estruturalmente, outras mulheres me permitiram isso. (Ana).

Outro aspecto importante é que ser a primeira da família a entrar na universidade aparece nas narrativas acompanhada pela necessidade de trabalhar para manter-se durante a graduação:

Durante um longo período, estudava durante a semana e cuidava de uma senhora idosa aos finais de semana. Veja bem, cuidar do outro mais uma vez atravessando o meu ser. (Maria).

A Comissão para Igualdade no Trabalho e Emprego (Portugal) aponta que o apoio insuficiente do estado em relação a subsídios e bolsas de estudo não permite que os estudantes se dediquem em tempo integral ao projeto curricular, necessitando, assim, trabalhar ${ }^{16}$. Além disso, o trabalho realizado para prover subsistência é geralmente informal, pois o setor privado não acata as determinações inscritas na lei do trabalhador-estudante, o que dificulta a conciliação dos horários de trabalho com as atividades acadêmicas. Tal colocação se mostra congruente com a realidade, pois manicure, garçonete, recepcionista e cuidadora de idosos foram as atividades laborais exercidas pelas quatro integrantes.

Ademais, as autoras também referiram que a necessidade de trabalhar concomitantemente à graduação foi um fator impeditivo para seu envolvimento em atividades extracurriculares como pesquisa e extensão:

Sempre estudei em escola pública, em uma cidade do interior gaúcho e a bolsa integral pelo ProUni foi a possibilidade de conquistar o diploma universitário em outra cidade e em uma universidade privada, o trabalho informal em lojas e bares foi a forma de me manter na cidade universitária, além das bolsas semestrais de monitoria de disciplina disponibilizadas pelo centro universitário. (Léia).

Estudantes de nível superior podem ser classificados como: estudante integral, estudante-trabalhador (estudo como principal atividade, mas exerce atividades remuneradas), e trabalhador-estudante (ocupação primária o trabalho, priorização das atividades laborais ao invés das acadêmicas). A diferença entre as classificações indica que os estudantes que precisam conciliar atividades laborais e de estudo possuem dificuldades para se envolver e realizar atividades além do ensino da sala de aula, como pesquisa, extensão e participação em eventos ${ }^{17}$.

\section{Privilégios e participação em pesquisa: desafios de ser mulher na academia com e sem outros marcadores sociais da diferença}

Para as narradoras, apesar das dificuldades, poder participar de um grupo de pesquisa e desenvolver atividades não remuneradas é resultado de uma série de privilégios não disponíveis a todas as mulheres no ambiente acadêmico:

Inclusive, integrar este grupo de pesquisa é mais uma demonstração do acesso à educação, conhecimento e experiência profissional que eu disponho. (Maria).

O fato de ter uma boa condição socioeconômica se configura um fator de privilégio, considerando que a pessoa pode se dedicar mais à academia e, também, adiar o período de formação, pois os currículos fechados colaboram para dificultar a participação em pesquisas e projetos de extensão. Além disso, é preciso ter experiência prévia para conseguir uma bolsa de pesquisa e de extensão, devido à importância dada ao currículo, de modo que muitas acadêmicas não conseguem atender aos critérios de participação e se formam sem ter participado de qualquer projeto. 
No que diz respeito ao gênero, em relação ao percentual de $19,6 \%$ de pessoas entre 25 e 34 anos que têm ensino superior, as mulheres representam mais de $70 \%$ da população formada na área da saúde, educação e ciências sociais, sendo minoria na área de engenharia. Entretanto, mesmo com esse alto número de formadas, ao longo da carreira, diminui-se drasticamente o número de mulheres que conseguem permanecer no papel de pesquisadora ${ }^{18}$.

Além disso, um estudo sobre bolsistas de produtividade do Conselho Nacional de Desenvolvimento Científico e Tecnológico (CNPq) verificou que há hegemonia de pesquisadores do gênero masculino, pois as áreas mais contempladas com bolsas são as ciências exatas e da terra e engenharia, campos nos quais historicamente há pouca concentração de mulheres ${ }^{19}$. Ademais, existe uma perpetuação de tais diferenças entre áreas do conhecimento e, apesar dos avanços alcançados pelas mulheres no campo das ciências, ainda há muitas iniquidades quando se comparam os papéis desempenhados por homens e mulheres nesses campos ${ }^{20}$.

O modo como ocorreu a inserção de mulheres no ensino superior no Brasil corroborou os estereótipos de gênero, que perpassam as feminilidades e masculinidades, em que as áreas relacionadas ao cuidado são compostas predominantemente por mulheres. Além disso, até hoje, o imaginário social é atravessado pela fantasia de que a contribuição de mulheres no ambiente acadêmico é afetada por fatores como: excesso de emotividade, dificuldade em desenvolver raciocínios abstratos e falta tempo para inserção na pesquisa devido ao trabalho doméstico ${ }^{21}$.

Assim, aponta-se que, muitas vezes, o ambiente acadêmico se mostra um espaço pouco inclusivo, pois embora haja um aumento na participação de mulheres nas universidades, a maioria delas enfrenta dificuldades para exercer suas funções devido à estrutura desigual das instituições e poucas chegam a postos de liderança no meio científico ${ }^{\mathbf{2 1}}$.
Apesar de as mulheres terem, em média, um nível de instrução superior ao dos homens em relação ao nível 'superior completo' e, especialmente, entre as pessoas da faixa etária mais jovens - 25 a 44 anos de idade 22 -, o número de mulheres diminui gradativamente nos níveis de mestrado e doutorado ${ }^{21}$. Alguns dos possíveis motivos para isso são o fato do início da carreira científica coincidir com o período fértil, tornando-se difícil acumular funções sociais de cuidado com a demanda da vida de cientista, além da dupla ou tripla jornada de trabalho, devido à divisão sexual do trabalho e à responsabilidade exclusiva das tarefas domésticas e criação dos filhos ${ }^{23}$. Por fim, tem-se que as escolhas que as mulheres fazem para conciliar sua tripla inserção na sociedade como mulher, mãe e cientista trazem prejuízos ou para a família ou para a profissão, o que sempre as deixa em uma situação de desvantagem na competição profissional com os homens.

Especificamente, no momento atual, tem-se que o impacto da pandemia na ciência brasileira está permeado e atravessado por questões de gênero, raça/etnia, classe e parentalidade. Um levantamento realizado pelo Movimento Parent in Science ${ }^{24}$ durante o isolamento social relativo à Covid-19 dos docentes pesquisadores de Institutos de Ensino Superior no País, a maioria das respondentes era de mulheres, brancas e com filhos, sendo apenas um terço dos respondentes homens. Contudo, entre as pessoas que estão conseguindo trabalhar remotamente e cumprir prazos para solicitação de fomentos, bolsas e submissão de artigos, a maioria foi de homens brancos; e entre as mulheres que conseguiram cumprir os prazos, a maior parte é branca e sem filhos. As mulheres negras são mais afetadas que as brancas com e sem filhos. Tal situação aparece também na narrativa de uma das autoras:

Como mulher branca, solteira e sem filhos não preciso conciliar trabalho e atividades acadêmicas com a esfera familiar e cuidado com os filhos, nem ter responsabilidade financeira com outras 
pessoas, além disso tenho o privilégio de ter ensino superior completo, ser residente multiprofissional em saúde mental com uma bolsa acima de três salários mínimos. (Léia).

Nesse sentido, a produtividade exigida pela academia é outro aspecto que se constitui como um grande desafio. Em relação a esse aspecto, a única narradora do grupo que é mãe apresenta dificuldades adicionais relacionadas com os parâmetros produtivos:

Sou cobrada, no ambiente acadêmico, da mesma forma que todos os outros colegas. Tenho pouquíssima produção de artigos e livros, o que inviabiliza o acesso a bolsas e editais mais concorridos. (Rosa).

Embora tenha tido, a cada gestação, seis meses adicionados ao meu prazo final, em nenhum momento considerou-se o fato de que tive uma gestação de risco, de que havia duas crianças, ou de que elas eram prematuras como fatos a serem considerados como elementos adicionais à minha necessidade de afastamento, ou a do meu companheiro. (Rosa).

A pressão por produtividade imposta pela academia faz com que, ao invés de serem legitimadas pelo aprofundamento teórico que realizam ou impactos e reflexões que promovem no outro, as pesquisadoras sejam valorizadas pelo volume de citações que dispõem, que, no que lhes concerne, tornam-se critérios de avaliações e condições para ingresso em programas de pesquisa ${ }^{25}$. Ademais, para discutir sobre a produção de conhecimento em profissões majoritariamente femininas, deve-se atentar para as questões de gênero, pois é importante reconhecer o que nos alinha no processo de produção científica e o que nos afasta do gênero oposto.

A forma inadequada como se dão as relações de gênero nos mais diferentes espaços também apareceu como elemento que dificulta tanto o acesso da mulher ao espaço público, incluindo a escola, a universidade e a pesquisa, quanto a sua permanência:
Nos três níveis de ensino, sofri e presenciei situações de assédio cometidos por professores e alunos homens e ouvi comentários e julgamentos extremamente preconceituosos sobre os mais diversos tópicos, incluindo sobre a forma como eu me vestia. (Bertha Lutz).

Tal situação também ocorreu durante as atividades da pesquisa desenvolvida pelas autoras, em que dua s integrantes do grupo, ao entrar em contato com dois homens participantes, foram assediadas com frases do tipo: "por que seu sorriso é tão bonito?" e "Que foto linda!!?"

Em vista disso, é preciso considerar as opressões sofridas pelas mulheres latino-americanas no processo de colonização do saber, de modo que a emancipação feminina nesses países requer uma produção científica sobre as opressões próprias do território ${ }^{22}$. Fraser $^{26-}$ 28 contribui para compreender e qualificar a participação de mulheres na construção de conhecimento a partir do conceito de justiça social e paridade participativa, em que coloca que a justiça social requer arranjos sociais que permitam a paridade participativa, que seria a possibilidade de todos participarem em condição de igualdade da vida social. Ela argumenta que a paridade participativa no espaço público é limitada mesmo quando todos os atores sociais estão presentes, como mulheres brancas. As dimensões culturais acarretam o estabelecimento de diferentes oportunidades e papéis para homens e mulheres tanto nas relações interpessoais quanto produtivas que se configuram como um fator limitante para a possibilidade de paridade participativa no ambiente acadêmico.

Para a existência de um mundo ocupacional mais justo, aqueles que pretendem viabilizar a justiça ocupacional devem ficar atentos às complexas relações de poder profissionais estabelecidas no ambiente de trabalho. Uma das estratégias é coletar e analisar histórias contadas por sujeitos que vivenciam injustiças cotidianas, pois, a partir delas, é possível gerar críticas e ideias que irão ajudar os profissionais 
na busca pela viabilização da justiça ocupacional nesses locais. Além disso, o desenvolvimento de projetos que reconheçam essas diferenças sociais relativas a gênero, raça/etnia e classe possibilita conscientizar as pessoas e encontrar colaboradoras para ir em busca da transformação dessa realidade ${ }^{29}$.

Não estou sozinha neste lugar, mas junto trago minha mãe, avó e tias. E, por isso, entendo que minha trajetória enquanto mulher pesquisadora tem não só uma responsabilidade afetiva, mas social. Se posso acessar o direito à educação, que seja para combater os privilégios que interditam tantas outras mulheres de ocupar esse mesmo espaço. (Ana).

\section{Apoio e cuidado mútuo entre elas}

\begin{abstract}
Com pouca disponibilidade de tempo e um currículo que não ajuda a conseguir bolsas, jamais teria sido possível integrar uma equipe de uma pesquisa desse tamanho sem contar com a solidariedade e a sororidade de todas as envolvidas: a coordenadora que assume as tarefas quando eu nem sei o que está acontecendo e as alunas de graduação e residência que assumem frentes mesmo quando pouco se pode oferecer em troca. (Rosa).
\end{abstract}

Eu não sei matar uma galinha ou qual a melhor época para plantar e colher batatas. Também não sei fazer bolachas. Mas sei ler, e hoje estou em um programa de pós-graduação. Hoje, sou uma mulher que pode se dedicar à pesquisa e à ciência porque as outras mulheres da minha família sustentaram a minha trajetória até aqui. Hoje eu sou porque elas foram. (Ana).

A sororidade como pensamento e exercício por meio da solidariedade entre mulheres, baseada na empatia, no respeito e no apoio mútuo, mostra-se um caminho efetivo de resistência à sociedade patriarcal que enfraquece a luta das mulheres ${ }^{30}$. A sororidade busca promover transformações sociais, políticas, econômicas, de trabalho e jurídicas, e não apenas das relações de gênero. Uma condição muito importante para a prática da sororidade que vai ao encontro desta narrativa é o compartilhamento de recursos, bens e espaços partindo de princípios como os de necessidade e prioridade para sustentar coletivamente aquelas que têm maiores necessidades e carências a partir do princípio ético da autonomia e do respeito de compromissos e liberdades.

Nesse sentido, as 'redes genealógicas' ganham importância enquanto redes de apoio que sempre existiram entre as mulheres, perpassam várias gerações, fazem parte do cotidiano e se constituem por intermédio do parentesco e da amizade, embora não escapem dos valores opressores do patriarcado, do capitalismo e do neoliberalismo. O que seria de nós, mulheres, sem as nossas avós, mães, filhas? O que seria de nós sem as nossas ancestrais ${ }^{30}$ ?

\section{Cuidadora: papel da mulher}

Eu tinha 12 anos, mas fui preparada desde os 9 anos pelas mulheres e homens da família a assumir os papéis de cuidado com a casa e com minha irmã mais nova. (Cristina).

Cuidei de crianças quando eu ainda era uma, sendo que fui babá dos 9 aos 16 anos e ainda exerço esse papel ocasionalmente. (Bertha Lutz).

O papel de cuidadora aparece na trajetória de vida das integrantes, tanto no cuidado de familiares quanto como atividade laboral que permite a complementação de renda, operando o dispositivo materno ${ }^{\mathbf{3 1}}$ como processo de subjetivação que valoriza mulheres que cumprem o papel de cuidadoras. Dessa forma, desde a infância, as meninas são educadas para o exercício do cuidado:

Durante minha infância, recordo de desejar cuidar do outro através do meu fazer. Naquele tempo, brincava cuidando das bonecas fantasiando que fossem filhas, cozinhava simbolicamente, brincava 
de médica e, sobretudo, como irmã mais velha, cuidava dos meus irmãos e carregava o peso de ser um exemplo positivo para eles. Cuidar sempre foi significativo na minha vida. (Maria).

O gênero é uma construção e convenção social, histórica e cultural determinada com base nas diferenças sexuais e delimita os papéis desempenhados por cada sexo na sociedade ${ }^{32}$. Tais papéis são impostos às crianças ainda na infância. As meninas devem vestir rosa, ser delicadas e brincar de 'casinha' e de boneca, além de serem estimuladas desde muito cedo a realizarem atividades domésticas e cuidarem de crianças menores. Já os meninos, por sua vez, devem brincar de super-heróis e carrinhos, além de serem encorajados a desmontar e construir coisas, atividades que propiciam o desenvolvimento do pensamento lógico e da capacidade de resolução de problemas. Assim, eles são estimulados a explorar e dominar o mundo, e elas são incentivadas a servir ao $l a r^{33}$. Desse modo, o gênero estrutura nossa autopercepção e a percepção de mundo, organizando a sociedade de forma concreta e simbólica ${ }^{32}$.

O desenvolvimento de atividades de cuidado ao longo da vida também aparece como fator que afeta a escolha profissional:

Ao longo deste tempo, profissionalmente, de forma quase espontânea, tornei-me terapeuta de criançase adolescentes. Era fácil e simples estar com eles. (Rosa).

A terapia ocupacional, criada durante a Revolução Industrial quando as mulheres ingressam no mercado de trabalho, constitui-se como profissão predominantemente feminina. $\mathrm{O}$ modelo de segregação de gênero tem forte influência no desenvolvimento das práticas profissionais dessa profissão, com seu fazer moldado pelas expectativas atribuídas ao gênero feminino ${ }^{34}$.

\section{Profissão de cuidado como escolha?}

Claro que ao chegar o vestibular eu só pensaria em uma profissão de cuidado e poder - a medicina.
Nasci de uma autorização médica, quase não tive irmã pela desautorização da mesma. (Cristina).

Outro aspecto comum ao grupo é o de ser composto por mulheres que escolheram profissões relacionadas com o cuidado, pois somos: cinco terapeutas ocupacionais formadas (duas docentes e três residentes), três acadêmicas do curso de terapia ocupacional e uma acadêmica do curso de psicologia. Além disso, as sete narradoras vivenciam esse espaço de cuidado antes mesmo da escolha profissional, como mencionado anteriormente.

D’Amorim ${ }^{35}$ estudou estereótipos de gênero, que incluem características físicas, psicológicas, comportamentais e ocupacionais. Em uma de suas pesquisas, cruzou a descrição de personalidade feminina, masculina e mista com diversas profissões e observou que as pessoas que leram a descrição feminina consideraram a pessoa descrita como gentil, emocional e compreensiva, com grandes chances de ser enfermeira, professora ou psicóloga, profissões que envolvem cuidado em menor ou maior grau.

O controle ideológico exercido nas relações de gênero tem dinâmicas de poder que são carregadas de dissimulações, de modo que as manifestações de poder nem sempre ocorrem pelas vias da repressão. Nesse sentido, existem redes pedagógicas, culturais, familiares e religiosas que, de forma sutil, disfarçadas de inocentes e até mesmo democráticas, constroem e perpetuam na sociedade um conjunto de disposições de identidades, práticas e estereótipos que irão ditar os comportamentos e os papéis que serão assumidos por gênero, incluindo a 'escolha' profissional ${ }^{36}$.

Então, a ordem social funciona como uma imensa máquina simbólica que tende a ratificar a dominação masculina na qual se alicerça: a divisão sexual do trabalho, que distribui de modo bastante restrito as atividades atribuídas a cada um dos dois sexos, de seu local, seus instrumentos. Hirata ${ }^{37}$ aponta uma concentração da atividade feminina em setores como saúde, educação e cuidados pessoais, o que pode ser explicado por Bourdieu ${ }^{38}$ pela divisão sexual 
do trabalho, a qual determina o interesse das mulheres por cursos e profissões reprodutivos de cuidados. Tal sistema sexuado está objetivado nas ocupações, atuando no prolongamento das funções domésticas, de ensino e de cuidado, além de conferir aos homens a autoridade e o monopólio de objetos técnicos e máquinas da esfera pública e postos de poder.

Faria ${ }^{39}$ aponta que essa construção é feita a partir das condições sociais em que os homens e as mulheres se encontram na sociedade. Diante disso, ainda presentemente vivemos em um sistema desigual, de superioridade e relações de poder ocorrendo no mundo do trabalho. Assim, salienta que chegarmos à equidade nas relações de gênero será resultado de como essas relações sociais são construídas e mantidas.

\section{Diploma como estratégia de libertação}

Algo que sempre ouvi desde criança é 'você tem que estudar, pois só a partir do estudo você consegue ser alguém na vida' e, apesar das problemáticas dessa frase de que só tive consciência mais tarde, de fato sempre levei a sério tal conselho. (Bertha Lutz).

Como filha de uma mulher guerreira, separada do meu pai, que foi embora da sua e minha cidade natal em busca de melhores condições de vida, que só terminou os estudos após os 25 anos de idade e até essa idade teve como atividade laboral ser empregada doméstica, fui influenciada fortemente a buscar meu lugar no mundo através dos estudos. (Léia).

Em muitas famílias, o acesso à universidade e a obtenção de um diploma possuem um significado tanto simbólico quanto prático. É simbólico porque é uma representação social que carrega consigo fatos históricos, legitima o ato da dedicação e simboliza a passagem de estudante para profissional ${ }^{40}$. Já a significação prática diz respeito à possibilidade de ocupar novos postos de trabalho com maior valorização social e remuneração financeira, além de ajudar as mulheres a evitarem a dependência financeira do seu eventual futuro companheiro. A ascensão socioeconômica também permite uma ascensão simbólica na medida em que a pessoa passa a ter mais acesso, não só a bens materiais, mas também sociais e culturais.

Cresci entre minha avó Luisa me ensinando a bordar, fazer tricot e crochê para poder casar e minha mãe dizendo que o diploma seria fundamental para que eu nunca, jamais, dependesse de homem algum. (Rosa).

Historicamente, no Brasil patriarcal, a mulher ideal deveria saber pouco ou quase nada. Com o tempo, as expectativas mudaram, e a escolarização feminina começou voltada para que as mulheres da elite brasileira fossem instruídas minimamente para viver em sociedade e serem agradáveis aos maridos e às pessoas com as quais eles mantinham relações de amizades ou negócios. Assim, as instruções destinadas à mulher não tinham nenhum teor de análise crítica da sociedade ou conteúdos científicos $^{32}$.

Consequentemente, o acesso ao ensino superior se destaca no processo mais amplo de escolarização feminina e é um importante marco das reivindicações feministas, pois esse espaço, além de ter sido tradicionalmente e quase unicamente ocupado por homens, também traz a representação da presença no mundo público e da aquisição não apenas de habilidades para o mercado de trabalho, mas também de novos valores e práticas ${ }^{41}$. A representação simbólica do diploma surge como meio de acesso aos lugares de valor social e aquisições de capitais simbólico, cultural e, sobretudo, econômico. Desse modo, a formação no ensino superior é vista como uma forma de mudar as condições sociais e culturais de origem ou de manter as condições sociais já favoráveis ${ }^{\mathbf{4 2}}$.

$\mathrm{O}$ acesso à universidade se traduz em ascensão social, oportunidade de concorrer a melhores postos de trabalho e possibilidade de ocupar postos controlados tradicionalmente 
por homens ${ }^{\mathbf{4 3}}$. Contudo, para as mulheres, nem mesmo seu grau de escolaridade tem assegurado igual reconhecimento profissional dos homens, pois mesmo quando têm maior escolaridade que os homens, ainda assim, enfrentam dificuldades para entrar em setores mais qualificados e, quando conseguem entrar, recebem menos em relação ao seu grau de instrução e em relação aos homens ${ }^{22}$.

Com o aumento da diplomação e qualificação profissional, as mulheres ingressaram no mercado de trabalho de forma mais intensa. No entanto, não houve a redistribuição das tarefas domésticas entre os membros da família, o que fez - e faz - com que a mulher assuma múltiplos papéis simultaneamente, causando uma enorme sobrecarga no acúmulo entre tarefas educacionais, profissionais e domésticas ${ }^{36}$. Esse modelo de conciliação entre vida profissional e vida familiar faz com que as mulheres, para focar na sua vida profissional, optem por delegar a outras mulheres as tarefas domésticas e de cuidado. Assim, cria-se uma bipolarização do trabalho feminino: de um lado, há mulheres com diplomas de nível superior, altamente qualificadas e com salários relativamente bons; do outro, existem mulheres com empregos vulneráveis e precários ligados especialmente a tarefas domésticas (empregadas e diaristas) e de cuidado (cuidadoras de crianças e de idosos). Dessa maneira, acentuam-se a divisão sexual do trabalho e as desigualdades sociais, não apenas de gênero, mas também de classes e de raças ${ }^{44}$. Portanto, mesmo o diploma sendo uma importante estratégia de libertação para as mulheres, especialmente econômica, este não garante a reconfiguração do trabalho de cuidado.

\section{Preconceito e medo}

Nos relatos, escolhas feitas pelas mulheres que fogem a um ideal social do que é ser mulher e de seu papel na sociedade surgem acompanhadas de reações preconceituosas:

Casei depois dos 35 anos de idade e chegando aos 40 anos sem filhos por escolha, já fui questionada por outras mulheres se eu era lésbica, por 'demorar' para arrumar um companheiro, ou por outras tantas mulheres, me adjetivando de egoísta por não querer ter filhos. Outras tentam me advertir sobre a solidão na fase idosa, sendo essas casadas e com filhos, mas aparentemente sozinhas. (Cristina).

O relacionamento amoroso é um dispositivo social de subjetivação das mulheres, em que a mulher é reconhecida socialmente enquanto sujeito com valor a partir de uma relação amorosa que a legitime. Enquanto o homem solteiro pode ser valorizado como desejável, a mulher solteira é vista socialmente como sem valor, aquela que "ninguém quis"31. Assim, investir na carreira é percebido como algo que é feito em detrimento de um investimento na vida familiar, aparecendo nas narrativas com o peso social de não reconhecimento.

Isso ocorre porque o olhar masculino reservou às mulheres uma imagem ambígua, atribuindo-lhes dois papéis distintos: o de Eva - forte, perigosa e pecadora - e o de Maria - mãe santa, zelosa, aquela que cumpre seu papel como procriadora sem desejo carnal e com obediência, um ideal a ser alcançado pelas mulheres honradas. Assim, têm-se as raízes pelas quais as mulheres ainda sofrem preconceitos quando desempenham e assumem outros papéis que não esses predefinidos ${ }^{32}$.

Em 1931, Virginia Woolf45 já questionava as atribuições destinadas ao feminino ao assumir a escrita como profissão. Havia uma relação direta entre o cuidado da vida doméstica, historicamente destinado às mulheres, e a interdição a outras ocupações laborais. Tal espectro, que rondava sua produção como escritora, foi denominado por ela de 'Anjo do Lar'; e percebeu que, se quisesse continuar escrevendo, seria necessário matar tal Anjo, essa criatura dócil, submissa, dedicada às tarefas de cuidado e manutenção da casa, criação dos filhos e cuidados com o marido. Entretanto, em uma sociedade patriarcal, matar o fantasma do Anjo do Lar não seria, e continua não sendo, uma tarefa simples.

Outro elemento presente nas narrativas é como ser mulher pode ser assustador. Léia 
refere que após ler o romance distópico 'Contos da Aia' ${ }^{\mathbf{6}}$ sentiu desconforto e medo:

Me causam revolta e sobretudo medo, medo de perder meus direitos, de perder minha voz, de perder meu lugar no mundo enquanto mulher, trabalhadora, estudante e cidadã. (Léia).

Apesar de os sentimentos de desconforto e medo emergirem a partir de uma obra de ficção distópica, é um tipo de narrativa que, mesmo fazendo uso do horror, tem sua potência no alerta, na mostra fantástica das tendências da sociedade moderna sem o freio da humanida$\mathrm{de}^{\mathbf{4 7}}$. O conto narra uma sociedade na qual as mulheres foram destituídas dos direitos que conquistaram, corroborando a afirmação de Simone de Beauvoir48(29):

Nunca se esqueça que basta uma crise política, econômica ou religiosa para que os direitos das mulheres sejam questionados. Esses direitos não são permanentes. Você terá que manter-se vigilante durante toda a sua vida.

\section{Ser mulher na linha de frente em um país extremamente desigual}

Além de participarem da atividade de pesquisa, três mulheres que compõem este exercício narrativo são residentes em serviços de saúde mental durante a pandemia:

Falo como residente na saúde mental, um campo do saber onde prevalece abordagem da psicopatologia e o conhecimento da psiquiatria e a psicologia. Falo como trabalhadora da saúde que continua desenvolvendo as atividades laborais durante a pandemia e ainda lidando com a ansiedade e o medo do contágio minha e dos colegas de trabalho. (Léia).

Mulheres constituem 70\% da força global de trabalho nos serviços sociais e da saúde, dado que enfatiza o gênero no trabalho em saúde e o risco de infecção que as trabalhadoras enfrentam. Durante o surto de Ebola na África
Ocidental, em 2014-2016, as mulheres foram mais propensas a serem infectadas pelo vírus devido aos seus papéis predominantes como cuidadoras nas famílias e como profissionais de saúde na linha de frente ${ }^{49}$. Em relação à saúde mental das mulheres na linha de frente, uma pesquisa feita durante o surto de Sars entre 2002-2003 no Canadá constatou que o núcleo da enfermagem (majoritariamente feminino) apresentou um maior nível de estresse quando comparado ao núcleo médico (principalmente masculino). Tal quadro foi atribuído pelo pesquisador como resultado das exigências do trabalho associado ao cuidado com a família, preocupação com a saúde de sua família e a de transmitir o vírus para esta ${ }^{50}$.

Na pandemia causada pela Covid-19, do total de profissionais da saúde infectados na Espanha e na Itália, 72\% e 66\%, respectivamente, eram mulheres ${ }^{51}$. Apesar de os homens morrerem mais pelo novo coronavírus, são as mulheres as pessoas afetadas de modo mais severo pela Covid-19, pois estão mais expostas ao risco de contaminação e às vulnerabilidades sociais decorrentes e aumentadas pela pandemia, como desemprego, aumento da pobreza, violência (taxas de violência doméstica aumentaram), falta de acesso aos serviços de saúde, entre outros ${ }^{52}$.

Além do papel como profissional da saúde, as mulheres desempenham um papel fundamental na manutenção da saúde de suas famílias, pois são responsáveis pela higiene do lar e dos membros da família, demonstram maior preocupação com a prevenção de doenças e agravos e, também, são responsáveis pelos cuidados dos membros da família quando estes estão doentes ${ }^{53}$.

O novo coronavírus não faz distinção de classe econômica, fronteiras, idiomas, sexo, raça/etnia e ideologias, podendo afetar a todos. Contudo, os impactos da pandemia são distintos, pois a desigualdade social e racial criam diferenciações ${ }^{54}$. Para as mulheres, o período de pandemia com as medidas de contenção para evitar a propagação do novo coronavírus resultou na acumulação e na intensificação das atividades de reprodução da vida, como a 
de esposa, mãe, doméstica, gerando injustiças ocupacionais, físicas e psíquicas ${ }^{55}$.

Além das mulheres, pobres e negros também são severamente afetados pela pandemia. A raça/etnia, assim como a classe, do ponto de vista das autoras, ainda é um grande balizador do acesso ao trabalho formal no Brasil, de modo que mulheres e pessoas negras de ambos os sexos representam a trabalhadora e o trabalhador informal, setor mais impactado na pandemia. Assim, mulheres e pessoas negras de ambos os sexos serão mais afetadas pela estagnação econômica e pela falta de circulação de pessoas nas cidades, empurradas para a informalidade. Além disso, tais grupos são aqueles que mais têm risco de se contaminar ${ }^{55}$.

Nesse sentido, segundo dados oficiais do Datasus, a vítima padrão do novo coronavírus no Brasil é homem, pobre e negro ${ }^{56}$. A primeira vítima do Rio de Janeiro era mulher e trabalhadora doméstica que pertencia a dois grupos de risco, seu vetor de contaminação foi a patroa, que havia voltado da Itália, e que não informou sobre a exposição ao risco e manteve contato com a trabalhadora, sem liberação devido ao risco ${ }^{57}$. Ademais, enquanto a morte de pessoas negras tem aumentado, a de brancos tem diminuído ${ }^{58}$. Tais fatos evidenciam desigualdades raciais e sociais à falta de ações efetivas do Estado com vistas a garantir os direitos básicos da população e a sua proteção social.

Em relação às variáveis de gênero e classe, a pesquisa Sem Parar, realizada entre abril e maio de 2020 , constatou que $8,4 \%$ das mulheres afirmaram ter sofrido alguma forma de violência no período de isolamento, sendo que, entre as participantes com renda familiar de até 1 salário mínimo residentes na área urbana, esse percentual sobe $12 \%$; e para as mulheres da área rural, para $11,7 \%$. Outro dado interessante apontado pela pesquisa é que $58 \%$ das mulheres desempregadas são negras, o que evidencia a interconexão entre raça/etnia e gênero ${ }^{59}$.

José Saramago, em uma entrevista para o jornal mexicano 'La Jornada', explanou que as misérias do mundo estão aí e só existem duas maneiras de reagir: entender que não temos nenhuma culpa nisso, encolher os ombros e dizer que não se tem poder para remediá-las; ou, então, assumir que, mesmo não tendo o poder de resolvê-las, é preciso agir como se o tivéssemos ${ }^{60}$.

Diante da situação de pandemia que estamos vivenciando, essa passagem corrobora as discussões atuais, pois os profissionais da área da saúde não conseguem sozinhos transformar as realidades sociais e/ou promover a cura do novo coronavírus, mas permanecem na linha de frente lutando com as condições que possuem, indignando-se com as situações desiguais de vida e correndo risco de se contaminarem em prol do cuidado do e para com o outro.

\section{Considerações finais}

Buscamos neste artigo refletir sobre nossas trajetórias a partir das narrativas e de referenciais teóricos que discutem o lugar e os papéis da mulher construídos socialmente e seus atravessamentos nos cotidianos de todas nós. A discussão passa pelos marcadores sociais de gênero, raça/etnia e classe e pela igualdade de direitos e acesso a espaços antes dominados pelos homens, como na ciência e nas universidades.

Nós, mulheres, professoras, mães, estudantes, filhas, esposas e pesquisadoras, urgimos por uma cultura em que caibam todas e todos, com a construção coletiva desse processo envolvendo os diferentes atores, em seus diversos papéis ocupacionais diante de uma pandemia e de uma sociedade excludente.

Gênero, raça/etnia e classe são fatores que podem ser privilégios ou obstáculos a depender de sua expressão como: masculino/ feminino, branca/negra, alta/baixa. No que diz respeito à classe, muitas pessoas perderam sua condição socioeconômica anterior à pandemia, de modo que a falta de equipamentos eletrônicos e de uma boa internet impede a participação em aulas, atividades e pesquisas 
virtuais - inclusive na que as autoras estão realizando - e a permanência na universidade. Em relação às mulheres, a maternidade, a divisão sexual e a dupla ou tripla jornada de trabalho contribuem ainda mais para a sub-representação feminina na ciência.

Assim, é inegável a necessidade de fortalecer discussões sobre os fatores que geram dificuldades para ingressar e permanecer na universidade, assim como de elaborar estratégias que promovam um ambiente acadêmico mais equalitário e empático. Precisamos adotar uma perspectiva em que a diversidade seja aceita e valorizada e produzir conhecimento aplicável no cotidiano e que transforme a realidade existente de exclusão para uma em que a verdadeira inclusão predomine. Por fim, é necessário que todas as pessoas participem desse processo e tenham consciência e um posicionamento ético sobre seus direitos e deveres, em romper com os estereótipos de gênero e promover uma educação crítica que fale sobre igualdade e equidade de gênero.

\section{Colaboradoras}

As autoras Dellbrügger AP (0000-00029430-6953)*, Oliveira MC (0000-0002-92516893)*, Guerra CR (0000-0002-0232-7504)*, Scaramussa CS (0000-0002-2656-1696)*, Ricci ÉC (0000-0003-3471-1479)* e Dimov T (00000002-7165-5245)* colaboraram substancialmente para a concepção, o planejamento, a análise e a interpretação dos dados. Todas as autoras acima citadas conjuntamente com Zorzi JG (0000-0001-8594-792X)* contribuíram significativamente para a elaboração do rascunho, revisão crítica do conteúdo e participaram da aprovação da versão final do manuscrito.

\section{Referências}

1. World Health Organization. World Federation of Occupational Therapists. Early Reabilitation in Conflits and Disasters. Global Rehabilitation Alliance; 2020. [acesso em 2020 jul 15]. Disponível em: https://hi.org/ sn_uploads/document/36199-Humanity--Inclusion-Clinical-Handbook-web_l.pdf.

2. Vasconcelos EM. Manual [de] ajuda e suporte mútuos em saúde mental: para facilitadores, trabalhadores e profissionais de saúde e saúde mental. Rio de
Janeiro: Escola do Serviço Social da UFRJ; Brasília, DF: Ministério da Saúde; Fundo Nacional de Saúde; 2013. [acesso em 2020 jul 30]. Disponível em: https:// historiapt.info/pars_docs/refs/10/9047/9047.pdf.

3. Richter IZ, Oliveira AM. Cartografia como metodologia: Uma experiência de pesquisa em artes visuais. Paralelo 31. 2018 [acesso em 2020 jul 15]; 1(8). Disponível em: https://periodicos.ufpel.edu.br/ojs2/index. php/paralelo/article/view/13292.
*Orcid (Open Researcher and Contributor ID). 
4. Benjamin W. O narrador: considerações sobre a obra de Nikolai Leskov. In: Benjamin W. Magia e técnica, arte e política: ensaios sobre literatura e história da cultura. São Paulo: Brasiliense; 1994. p. 123-9. [acesso em 2021 set 22]. Disponível em: http://www.usp. br/cje/depaula/wp-content/uploads/2017/03/O-Narrador_Walter-Benjamin-1.pdf.

5. Belli G, Vasques J. Conselhos para a mulher forte. Eu Passarin. 2015 [acesso em 2020 jul 30]. Disponível em: https://eupassarin.wordpress.com/2015/01/07/ conselhos-para-a-mulher-forte/.

6. Oliveira MS. Marcadores Sociais da Diferença: Experiência educacional através do Museu da Empatia. [monografia]. Niterói: Universidade Federal Fluminense; 2018. 52 p. [acesso em 2020 ago 1]. Disponível em: https://app.uff.br/riuff/handle/1/9868.

7. Sousa KCS, Barros JDV. Estereótipos étnicos e representações sociais: uma breve incursão teórica. Rev. Educ. Emancipação. 2012; 5(2):199-224.

8. Hirano LFK, Acuña M, Machado BF, organizadores. Marcadores sociais das diferenças: fluxos, trânsitos e intersecções. Goiânia: Editora Imprensa Universitária; 2019. 285 p. (Coleção Diferenças). [acesso em 2020 ago 1]. Disponível em: https://files.cercomp.ufg. br/weby/up/688/o/marcadores_sociais_das_diferencas.pdf.

9. Lemos IBD. Narrativas de cotistas raciais sobre suas experiências na universidade. Rev. Bras. Educ. 2017 [acesso em 2020 jul 30]; 22(71). Disponível em: http://www.scielo.br/scielo.php?script=sci abstract\&pid=S1413-24782017000400226\&lng=en \&nrm=iso\&tlng=pt.

10. hooks B. Mulheres negras: moldando a teoria feminista. Rev Bras Ciênc Polít. 2015 [acesso em 2020 jul 30]; (16):193-210. Disponível em: https://doi. org/10.1590/0103-335220151608.

11. Quadros W. Gênero e raça na desigualdade social brasileira recente. Estud av. 2004 [acesso em 2020 jul 30]; 18(50):95-117. Disponível em: https://doi.org/10.1590/ S0103-40142004000100010.
12. Ribeiro M. Mulheres Negras: Uma Trajetória de Criatividade, Determinação e Organização. Estud. Fem. 2008 [acesso em 2020 jul 30]; 16(3):9871004. Disponível em: https://doi.org/10.1590/S0104$-026 \mathrm{X} 2008000300017$.

13. Silva VC, Silva WS. Marcadores sociais da diferença: uma perspectiva interseccional sobre ser estudante negro e deficiente no Ensino Superior brasileiro. Rev Educ Espec. 2018 [acesso em 2020 jul 30]; 31(62):569. Disponível em: http://dx.doi.org/10.5902/1984686X.

14. Schucman LV. Entre o "encardido", o "branco" e o "branquíssimo": Raça, hierarquia e poder na construção da branquitude paulistana. [dissertação]. São Paulo: Instituto de Psicologia, Universidade de São Paulo; 2012. 122 p. [acesso em 2020 jul 30]. Disponível em: https://www.teses.usp.br/teses/disponiveis/47/47134/tde-21052012-154521/publico/schucman_corrigida.pdf.

15. Nogueira IB. Significações do Corpo Negro. [dissertação]. São Paulo: Universidade de São Paulo; 1998. 146 p. [acesso em 2020 jul 30]. Disponível em: http:// www.ammapsique.org.br/baixe/corpo-negro.pdf.

16. Guerreiro MD, Abrantes P. Transições Incertas: Os jovens perante o trabalho e a família. Lisboa: Comissão para a Igualdade no Trabalho e no Emprego; 2007 [acesso em 2020 jul 30]. Disponível em: http://cite. gov.pt/imgs/downlds/Transicoes_Incertas.pdf.

17. Terribili Filho A. Educação Superior no Período Noturno: Impacto do Entorno Educacional no Cotidiano do Estudante. [tese]. [Marília]: Universidade Estadual Paulista, Faculdade de Filosofia e Ciências; 2007. 187 p. [acesso em 2020 jul 30]. Disponível em: https://repositorio.unesp.br/handle/11449/104842.

18. Instituto Brasileiro de Geografia e Estatística. Síntese de Indicadores Sociais: Uma análise das condições de vida da população brasileira. IBGE; 2018. [acesso em 2020 jul 24]. Disponível em: https://biblioteca. ibge.gov.br/visualizacao/livros/liv101629.pdf.

19. Guedes MC, Azevedo N, Ferreira LO, et al. A produtividade científica tem sexo? Um estudo sobre bolsis- 
tas de produtividade do CNPq. Cadernos Pagu. 2015 [acesso em 2020 jul 28]; (45):367-99. Disponível em: https://doi.org/10.1590/18094449201500450367.

20. Grossi MGR, Borja SDB, Lopes AM, et al. As mulheres praticando ciência no Brasil. Rev Estud Fem. 2016 [acesso em 2020 jul 28]; 24(1):11-30. Disponível em: https://doi.org/10.1590/1805-9584-2016v24nlp11.

21. Vasconcellos BM, Lima MMT. Fanny Tabak e os primeiros passos dos estudos sobre Ciência, Tecnologia e Gênero no Brasil. REDES. 2016 [acesso em 2020 jul 23]; 22(43):13-32. Disponível em: http://ridaa.unq. edu.ar/handle/20.500.11807/1123.

22. Instituto Brasileiro de Geografia e Estatística. Estatísticas de gênero: indicadores sociais das mulheres no Brasil. Rio de Janeiro: IBGE, Coordenação de População e Indicadores Sociais; 2018. (Coleção Ibgeana; Estudos e pesquisas. Informação demográfica e socioeconômica). [acesso em 2020 jul 28]. Disponível em: https://biblioteca.ibge.gov.br/index.php/biblioteca-catalogo?view=detalhes $\&$ id $=2101551$.

23. Lima BS, Braga ML, Tavares I. Participação das mulheres nas ciências e tecnologias: Entre espaços ocupados e lacunas. Rev. Gênero. 2015 [acesso em 2020 jul 22]; 16(1):11-31. Disponível em: https://doi.org/10.22409/ rg.v16il.743.

24. Parent in Science. Produtividade Acadêmica Durante a Pandemia: Efeitos de gênero, raça e parentalidade. Parent in Science; 2020. [acesso em 2020 jul 28]. Disponivel em: https://327b604e-5cf4-492b-910be35e2bc67511.filesusr.com/ugd/0b341b_81cd8390d of94bfd8fcd17ee6f29bc0e.pdf?index=true.

25. Galheigo SM. Sobre identidades, latinoamericanidades e construção de saberes em Terapia Ocupacional: diálogos com Boaventura de Sousa Santos. Cad. Ter. Ocup. UFSCar. 2014 [acesso em 2020 jul 28]; 22(1):215-21. Disponível em: https://doi.org/10.4322/ cto.2014.023.

26. Fraser N. Mercantilização, proteção social e emancipação: as ambivalências do feminismo na crise do capitalismo. Rev. Direito GV. 2011 [acesso em 2020 jul 28];
7(2):617-634. Disponível em: https://doi.org/10.1590/ S1808-24322011000200011.

27. Fraser N. Reframing justice in a globalizing world. Lua Nova: Revista de Cultura e Política. 2009 [acesso em 2020 jul 28]; (77):11-39. Disponível em: https:// doi.org/10.1590/S0102-64452009000200001.

28. Fraser N. Reconhecimento sem ética. Lua Nova: Revista de Cultura e Política. 2007 [acesso em 2020 jul 28]; (70):101-138. Disponível em: https://doi.org/10.1590/ S0102-64452007000100006.

29. Townsend E, Marval R. Can professionals actually enable occupational justice? Cad. Ter. Ocup. UFSCar. 2013 [acesso em 2020 jul 28]; 21(2):215-28. Disponível em: http://doi.editoracubo.com.br/10.4322/ cto.2013.025.

30. Becker MR, Barbosa CM. Sororidade em Marcela Lagarde y de los Ríos e experiências de vida e formação em Marie-Christine Josso e algumas reflexões sobre o saber- fazer-pensar nas ciências humanas. Coisas do Gênero. 2016 [acesso em 2020 jul 28]; 2(2):14. Disponível em: http://periodicos.est.edu.br/index.php/ genero/article/view/2883.

31. Zanello V. Saúde mental, mulheres e conjugalidade. In: Stevens C, Oliveira S, Zanello V, organizadores. Estudos Feministas e de Gênero: Articulações e Perspectivas. Ilha de Santa Catarina: Mulheres; 2014. p. 108-18. [acesso em 2021 set 22]. Disponível em: https://repositorio.unb.br/bitstream/10482/16349/1/ LIVRO_EstudosFeministasedeGeneroArticula\%c3 \%a7\%c3\%b5es.pdf.

32. Follador KJ. A mulher na visão do patriarcado brasileiro: uma herança ocidental. Rev. fato vers. 2009 [acesso em 2020 jul 28]; 2(1):3-16. Disponível em: https://www.academia.edu/3784126/A_MULHER_NO_ PATRIARCADO_BRASILEIRO.

33. Lazzarini AB, Sampaio CP, Gonçalves VS, et al. Mulheres na ciência: papel da educação sem desigualdade de gênero. Rev Ciênc Ext. 2018 [acesso em 2020 jul 28]; 14(2):188-194. Disponível em: https://ojs.unesp. br/index.php/revista_proex/article/view/1717. 
34. Zambulim MC, Emmel MLG, Fornereto APN, et al. Terapia ocupacional: uma profissão relacionada ao feminino. Hist cienc saude-Manguinhos. 2018 [acesso em 2020 jul 28]; 25(1):115-26. Disponível em: https://doi.org/10.1590/S0104-59702018000100007.

35. D’Amorim MA. Estereótipos de gênero e atitudes acerca da sexualidade em estudos sobre jovens brasileiros. Temas em Psicol. 1997 [acesso em 2020 jul 28]; 5(3). Disponível em: http://pepsic.bvsalud.org/scielo.php?script=sci_arttext\&pid=S1413-389 X1997000300010.

36. Ávila RC, Portes ÉA. A tríplice jornada de mulheres pobres na universidade pública: trabalho doméstico, trabalho remunerado e estudos. Rev Estud. Fem. 2012 [acesso em 2020 jul 28]; (20):809-832. Disponível em: https://doi.org/10.1590/S0104-026X2012000300011.

37. Hirata H. Globalização e divisão sexual do trabalho. Cadernos pagu. 2002 [acesso em 2020 jul 28]; (17/18):139-156. Disponível em: https://www.scielo. br/j/cpa/a/PcsfvS6CPpgQRZLRmdTzgxL/?lang=pt \&format=pdf.

38. Bourdieu P. A dominação masculina. Rio de Janeiro: Bertrand Brasil; 2014.

39. Faria IB. A trajetória das mulheres na ciência: as consequências e os desafios de produzir conhecimento em um mundo historicamente masculino. Juiz de Fora: UFJF; 2018. [acesso em 2020 jul 28]. Disponível em: https://www.ufjf.br/bach/files/2016/10/ IZABELLA-BARCELLOS-FARIA.pdf.

40. Carvalho AP, Lopes Neto D, Silva NC. Significado dos rituais de formaturas para os egressos da Escola de Enfermagem de Manaus/AM (1955 - 2010). Hist. Enferm. Rev Eletr. 2015 [acesso em 2020 jul 28]; 6(1):13. Disponível em: http://here.abennacional.org.br/here/4_AO_10015_MM.pdf.

41. Guedes MC. A presença feminina nos cursos universitários e nas pós-graduações: desconstruindo a ideia da universidade como espaço masculino. Hist cienc saude-Manguinhos. 2008 [acesso em 2020 jul 28]; 15(supl):117-32. Disponível em: https://www.scielo.
br/j/hcsm/a/tPvR4dWz5GzGCgn4c6GCZHp/?for mat=pdf\&lang=pt.

42. Oliveira JÉPL, Soares JGS, Sousa RN. As Representações Sociais sobre a qualidade da educação das faculdades particulares: Uma abordagem política, social e histórica. In: Anais X Congresso Nacional de Educação. 7-10 Nov. Curitiba. Curitiba: PUC-Paraná; 2011.

43. Estereótipos de gênero e atitudes acerca da sexualidade em estudos sobre jovens brasileiros. Temas em Psicol. 1997 [acesso em 2020 jul 28]; (3):121-35. Disponível em: http://pepsic.bvsalud.org/scielo.php?script=sci arttext\&pid=S1413-389X1997000300010.

44. Hirata H. Emprego, responsabilidades familiares e obstáculos sócio-culturais à igualdade de gênero na economia. Rev Observat. Brasil da Iguald. Gênero. 2010 [acesso em 2020 jul 28]; (1):45-9. Disponível em: https://www.gov.br/mdh/pt-br/navegue-por-temas/ politicas-para-mulheres/arquivo/central-de-conteudos/publicacoes/publicacoes/2010/revista_2edicao_ trabalho_dez2010.pdf $\#$ page $=47$.

45. Woolf V. Profissões para mulheres e outros artigos feministas. Porto Alegre: L\&PM Editores; 2012.

46. Atwood ME. O Conto da Aia. Rio de Janeiro: Rocco; 2006.

47. Arbo JB, Marques EM. Confinadas em si mesmas: a morte social e o isolamento do sujeito em $\mathrm{O}$ conto da aia, de Margaret Atwood. Anu Lit. 2019 [acesso em 2020 jul 28]; 24(2):164-76. Disponível em: https:// dialnet.unirioja.es/servlet/articulo? codigo $=7276439$.

48. Beauvoir S. O Segundo Sexo. Rio de Janeiro: Nova Fronteira; 1949.

49. Fundo de População das Nações Unidas. COVID 19: Um olhar para Gênero. New York: UNFPA; 2020. [acesso em 2020 jul 28]. Disponível em: https://brazil.unfpa.org/sites/default/files/pub-pdf/covid19_ olhar_genero.pdf.

50. Instituto de Pesquisa Econômica Aplicada. Prevenindo conflitos sociais violentos em tempos de pande- 
mia: garantia da renda, manutenção da saúde mental e comunicação efetiva. 2020. [acesso em 2020 jul 28]. Disponível em: repositorio.ipea.gov.br/bitstream/11058/9836/1/NT_27_Diest_Prevenindo\%20 Conflitos\%20Sociais\%20Violentos\%20em\%20Tempos\%20de\%20Pandemia.pdf.

51. Organização Pan-americana da Saúde. Organização Mundial da Saúde. Gênero e COVID-19: Orientações para Advocacy. [acesso em 2020 jul 20]. Disponível em: http://iris.paho.org/bitstream/handle/10665.2/52432/OPASWBRACOVID-1920085_ por.pdf?sequence=1\&isAllowed=y.

52. Modelli L, Matos T. Como a pandemia de coronavírus impacta de maneira mais severa a vida das mulheres em todo o mundo. G1. 2020 abr 19 [acesso em 2020 jul 28]. Disponível em: https://g1.globo.com/ bemestar/coronavirus/noticia/2020/04/19/como-a-pandemia-de-coronavirus-impacta-de-maneira-mais-severa-a-vida-das-mulheres-em-todo-o-mundo.ghtml.

53. Fundo de Desenvolvimento das Nações Unidas paras as Mulheres. O Progresso das Mulheres no Mundo (2008-2009): Quem responde às mulheres? Gênero e responsabilização. [acesso em 2020 jul 20]. Disponível em: http://www.onumulheres.org.br/wp-content/uploads/2019/11/Portuguese-POWW-2008-indd.pdf.

54. Daltro MR, Barreto Segundo JD. A pandemia nos mostra quem somos? Rev Psi Divers Saúde. 2020 [acesso em 2020 jul 21]; 9(1):5. Disponível em: https://doi. org/10.17267/2317-3394rpds.v9i1.2844.

55. Helene D. “Eu quero sair daqui!": do isolamento doméstico a coletivização do cuidado. In: Borges A, Marques L, organizadores. Reflexões durante a pan- demia: coronavírus e as cidades no Brasil. Rio de Janeiro: Outras Letras; 2020.

56. Soares M. Dados do SUS revelam vítima-padrão de Covid-19 no Brasil: homem, pobre e negro. Época. 2020. [acesso em 2020 jul 22]. Disponível em: https:// epoca.globo.com/sociedade/dados-do-sus-revelam-vitima-padrao-de-covid-19-no-brasil-homem-pobre-negro-24513414

57. Melo ML. Primeira vítima do RJ era doméstica e pegou coronavírus da patroa no Leblon. UOL Notícias. 2020 mar 19. [acesso em 2020 jul 23]. Disponível em: https://noticias.uol.com.br/saude/ultimas-noticias/ redacao/2020/03/19/primeira-vitima-do-rj-era-domestica-e-pegou-coronavirus-da-patroa.htm.

58. Muniz B, Fonseca B, Pina R. Covid-19: mortes de negros e pobres disparam. Outras Palavras. [acesso em 2020 jul 21]. Disponível em: https://outraspalavras. net/outrasmidias/covid-19-mortes-de-negros-e-pobres-disparam/.

59. Sempreviva Organização Feminista. Sem Parar: o trabalho e a vida das mulheres na pandemia. [acesso em 2020 jul 21]. Disponível em: http://mulheresnapandemia.sof.org.br/.

60. Aguilera FG, organizador. As palavras de Saramago. Rio de Janeiro; São Paulo: Cia das Letras; 2010.

\footnotetext{
Recebido em 30/08/2020

Aprovado em 01/09/2021

Conflito de interesses: inexistente

Suporte financeiro: não houve
} 